\title{
Ear Parade: A Call for Preventive Actions to Strengthen the Healthcare System against Hearing Loss
}

\author{
Paula Tardim Lopes ${ }^{10}$ Ricardo Ferreira Bento ${ }^{10}$ \\ ${ }^{1}$ Department of Otorhinolaryngology, Universidade de São Paulo, \\ SP, Brazil \\ Int Arch Otorhinolaryngol 2021;25(4):e530-e535.
}

\begin{abstract}
Address for correspondence Paula Tardim Lopes, MD, Department of Otorhinolaryngology, Universidade de Sao Paulo, Av. Dr. Enéas de Carvalho Aguiar, 255, $6^{\circ}$ Andar, Sala 6167, São Paulo, 05403-000, Brazil (e-mail: paulatardimlopes@gmail.com).
\end{abstract}

\begin{abstract}
Introduction Approximately 10 million people in Brazil have some hearing impairment. Because of the natural progression of hearing impairment to presbycusis, coupled with the increasing number of young people exposed to the risk factors for early hearing loss, the social impact of hearing impairment is high.

Objective A team of otolaryngologists and speech therapists conducted an unprecedented worldwide campaign in the primary health sector, aiming to reduce the global burden of hearing impairment with preventive measures.

Methods A cultural information campaign called "Ear Parade" was developed. It lasted 3 months, during which São Paulo received information on the prevention of deafness and the importance of hearing rehabilitation to reduce prejudice against the use of hearing aids.

Results The information was relayed through an art exhibition of public paintings, including 62 sculptures of ears, 2.40 meters high, which colored the city, elucidating

\section{Keywords}

- deafness

- hearing loss

- prevention

- healthcare

- dementia

- prejudice the beauty of hearing. The media coverage impacted 170 million people, and at the end of the campaign, a nongovernmental organization was established to raise resources for hearing rehabilitation. In addition, an auction of the ear sculptures raised money toward hearing aid batteries and stem-cell research for hearing.

Conclusion The present paper presents the effects of this campaign. Information dissemination is a powerful preventive measure for the primary healthcare system to reduce future treatment expenditures.
\end{abstract}

\section{Introduction}

Hearing impairment has been detected in 9.8 million Brazilians who represent $5.2 \%$ of the Brazilian population. ${ }^{1}$ The World Health Organization (WHO) estimated that $\sim 360$ million individuals live with hearing loss (HL), including $\sim 32$ million (9\%) children and 328 million (91\%) adults. Furthermore, it has been estimated that $\sim 500$ million individuals $>65$ years old will have HL by $2050 .^{2}$

received

October 15, 2019

accepted

March 16, 2020

published online

December 8, 2020
As for the world prevalence, it is known that between 5 and $6 \%$ of the world population has some hearing impairment, and $\sim 2 \%$ of the world population has severe to profound HL. The number of elderly people with HL is increasing, and almost $100 \%$ will have $\mathrm{HL}$ in the future. Severe and profound $\mathrm{HL}$ affects between 1 and 6 per 1,000 normal live births and between 1 and 4 per 100 newborns attended to in neonatal intensive care units.

The results of the most recent studies on Global Burden of Disease indicate a growing and alarming burden of $\mathrm{HL}$.
DOI https://doi.org/ 10.1055/s-0040-1712480 ISSN 1809-9777.

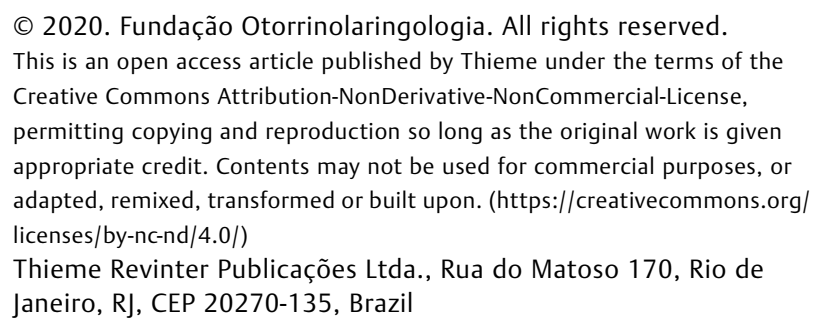


Globally, 1 in 3 adults has some level of measurable HL, and 1.1 billion young individuals are at a risk for $\mathrm{HL}$ attributable to noise exposure. Although noisy occupations are the primary cause of $\mathrm{HL}$ in adults, nonoccupational and recreational noise due to the use of headphones can also damage hearing, and their prevalence is increasing, especially in young adults. ${ }^{3,4}$

Emphasis on the prevention and treatment of juvenile and childhood HL could reduce the burden of HL in countries at lower levels of economic prosperity and sociodemographic indexes.
Current best practices in hearing healthcare indicate many additional conditions of change for hearing healthcare worldwide and offer recommendations to first stop the burden of HL growth and subsequently reduce it. ${ }^{5}$

The disability caused by HL largely depends on a person's communication needs and affects their ability to function professionally and socially.

The absence or substantial attenuation of auditory inputs to the brain alters neuronal connectivity and processing in

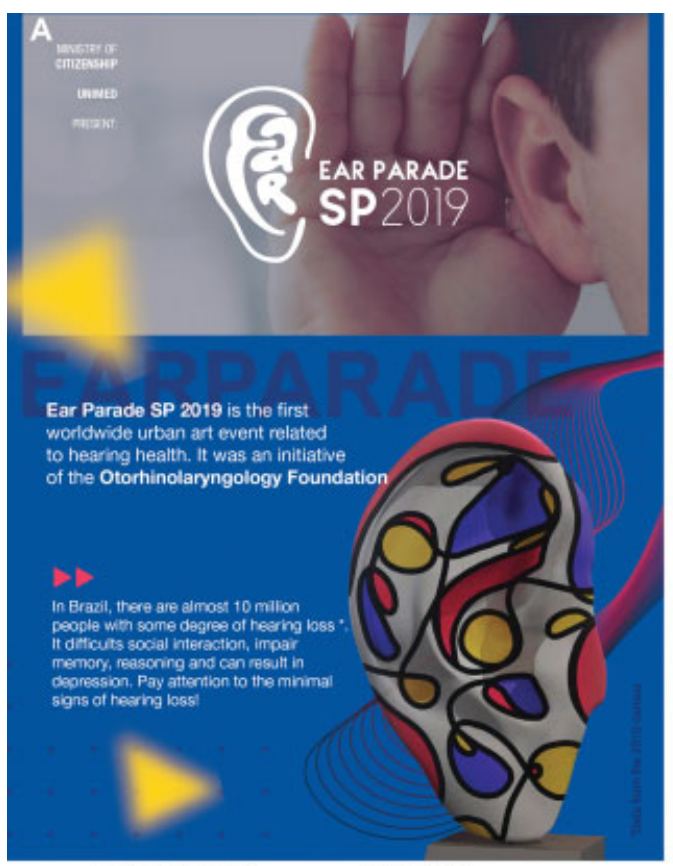

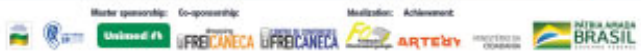

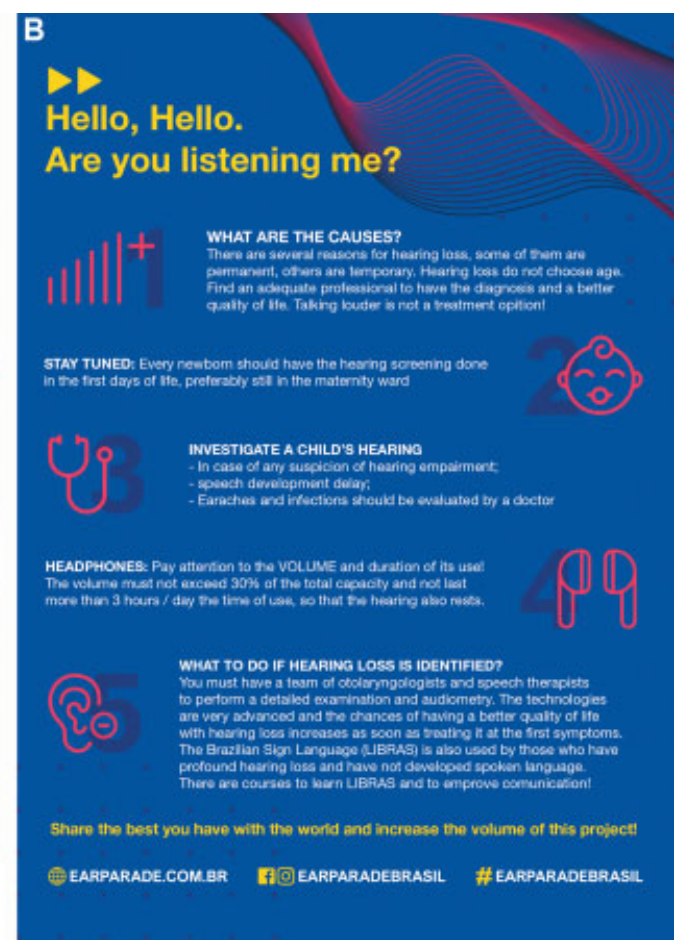

Fig. 1 An informative folder on preventive strategies against deafness.

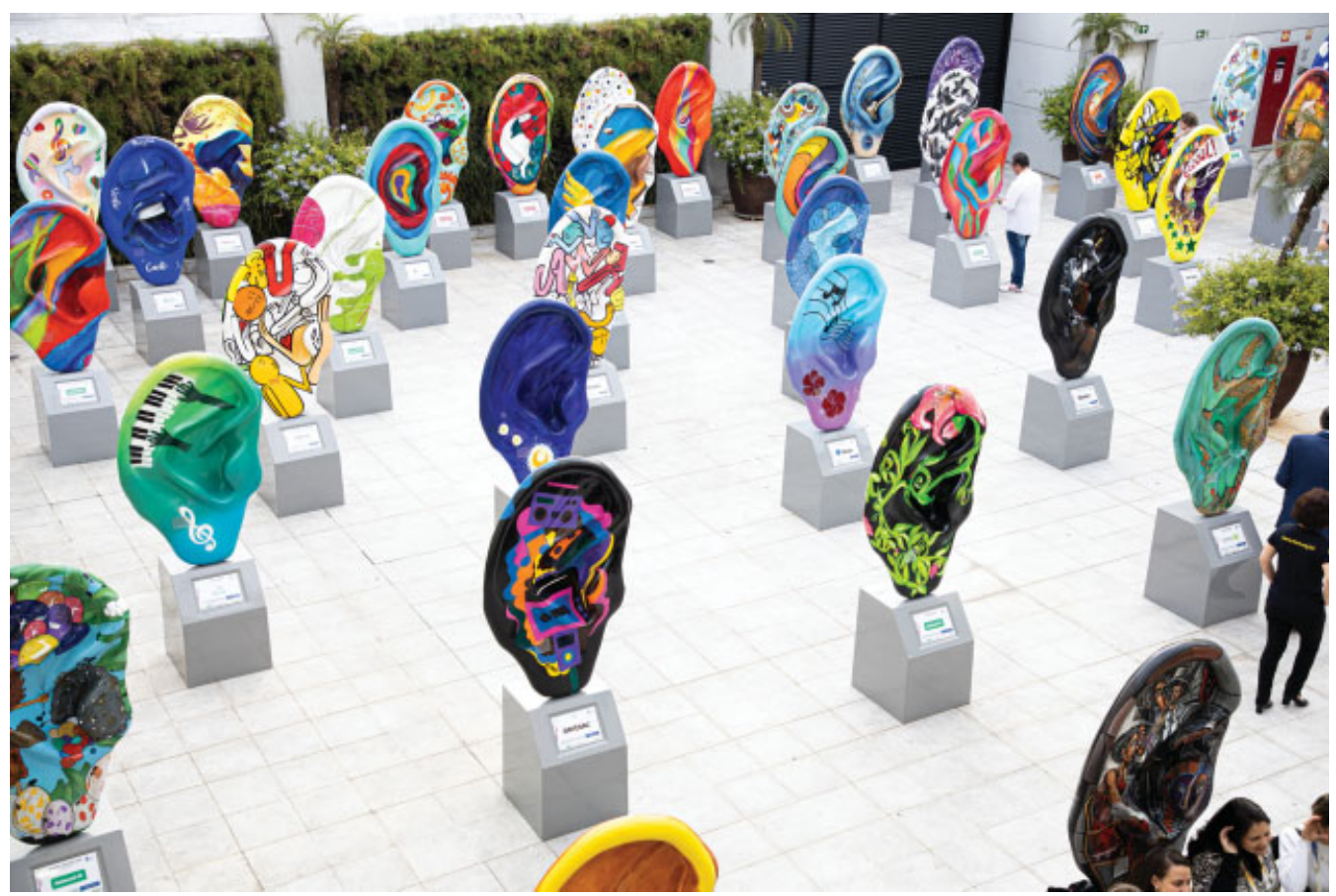

Fig. 2 Final exhibition of ears. 
the brain, especially before the age of 3 years old and perhaps again after the age of 60 years old. ${ }^{6}$

Children with severe or profound HL have lower literacy than their normal-hearing peers, and their educational achievements are severely compromised. ${ }^{7}$

Most adults with disabling HL have a feeling of deep isolation and typically distance themselves from society and family. ${ }^{8}$

Many people with HL try to hide it because it is commonly associated with aging and low intelligence. Stigma may hinder treatment and greatly reduce the self-esteem of the individual. $^{9}$

Psychological illnesses are more prevalent in individuals with HL than in the general population. ${ }^{10}$

An increasing number of significant associations have been demonstrated between HL in older people (aged $\geq 60$ years old $)^{3}$ and several negative health outcomes, including dementia. $^{11-13}$
In the 2017 Global Burden of Disease study by Lancet, HL ranked $4^{\text {th }}$ among 347 illnesses associated with the years lived with disability.

According to the WHO, $\sim 50 \%$ of the cases of HL could be avoided, and most of the rest could be treated effectively. ${ }^{14}$

\section{Objectives}

Prevention is usually better than cure, as it is less expensive and can often be implemented at the community level. The avoidable causes of HL include otitis media, maternal rubella, other infectious diseases, birth defects, excessive use of ototoxic drugs, consanguinity, and exposure to harmful noise levels. Awareness of these conditions should be increased among the population.

Individuals are exposed to a wide range of potentially harmful noise sources in their daily life but lack awareness
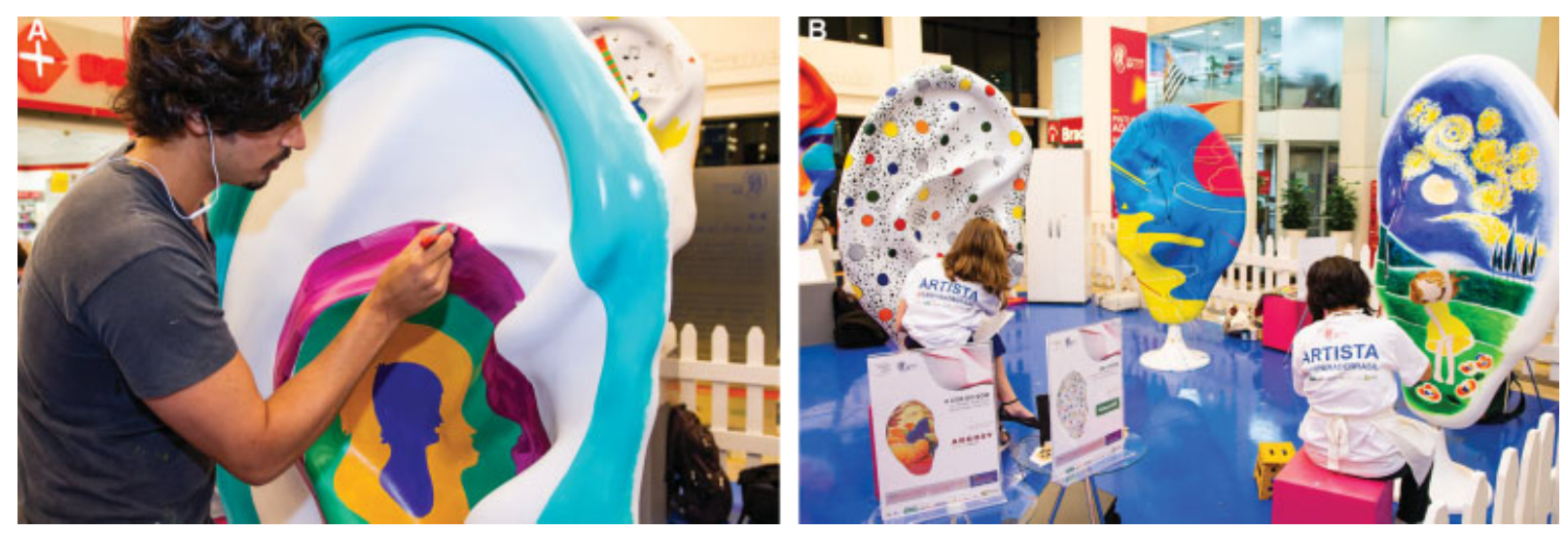

Fig. 3 A public studio with 62 giant sculptures of ears, each $2.40 \mathrm{~m}$ in length, painted during a period of 2 months and the public walk.

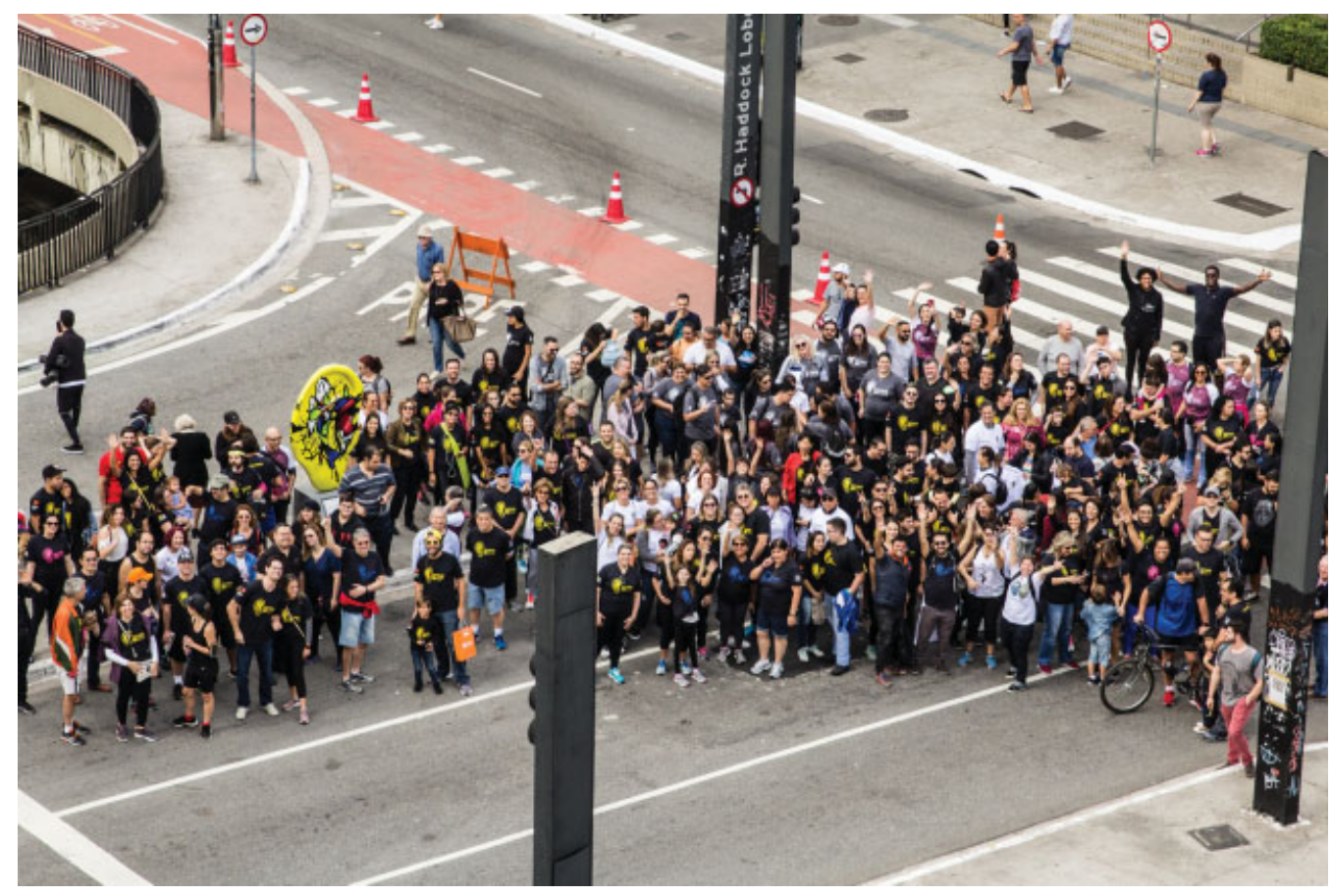

Fig. 4 Streets exhibition of ears. 
regarding the method of prevention of $\mathrm{HL}$ and the role of these noises in the decline in hearing health.

Harmful sound damages the cochlear cells, causing permanent HL through metabolic exhaustion or mechanical destruction of the sensory cells in the cochlea. Noise exposure standards should be promoted in the workplace at the 85$\mathrm{dB}$ limit for an average daily exposure of 8 hours. Individuals should be made aware that each increment of $3 \mathrm{~dB}$ in the exposure level reduces the recommended exposure time by half. Therefore, an 88-dB exposure limit is recommended for up to 4 hours and a $91-\mathrm{dB}$ exposure limit for 2 hours. $^{15}$

\section{Methods}

Otolaryngologists and audiologists conducted a Cultural and Health Campaign to promote hearing healthcare by
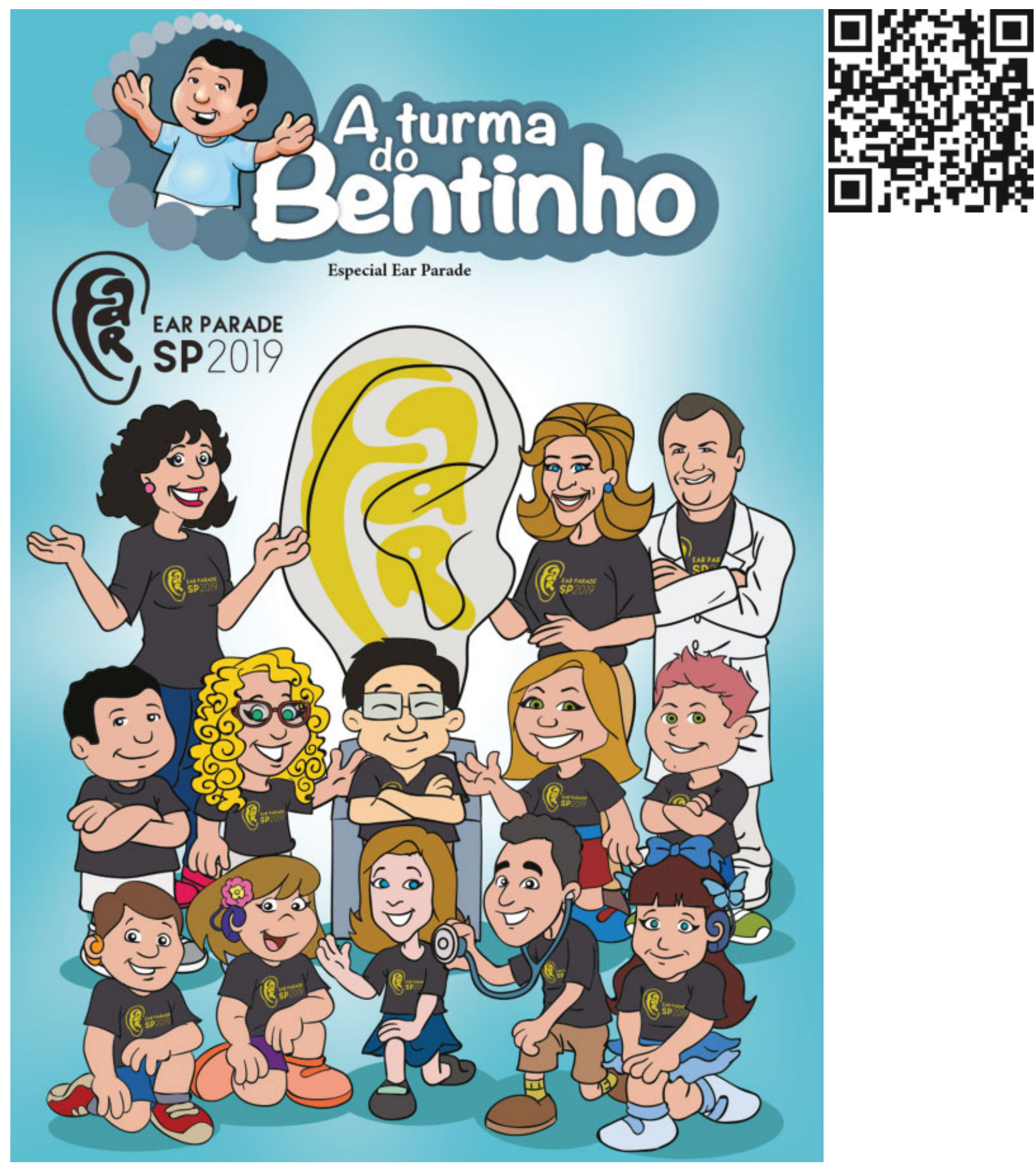

Fig. 5 Children's magazine called "Turma do Bentinho" promoting knowledge on strategies for prevention of hearing loss aimed at sensitizing children to the prejudice toward individuals with hearing impairment or hearing aids. 
guiding the population and encouraging rehabilitation programs.

Scientific explanations were provided to the population for 2 months, and a nongovernmental organization called "Otorhinolaryngology Foundation in Brazil" supported the creation of the campaign "Ear Parade," which was the first urban art event focused on the cause of hearing health. It was a cultural campaign that presented art in the form of 60 giant-ear sculptures exhibited in São Paulo, which is the biggest and most noisy Brazilian metropolis.

The Ear Parade Campaign focused primarily on preventive strategies by providing correct information to the population on the symptoms, early diagnosis, and prevention strategies of HL and steps to ensure access to necessary rehabilitation services and communication tools. All these messages were conveyed through a big, exclusive art exhibition on this topic (-Fig. 1).

A democratic registration was opened for creating over 62 giant-ear sculptures, and 30 artists were selected for this work (-Fig. 2). In addition to the educational material created to guide the population, many direct media covered the project. Repercussions of the campaign, initially headquartered in São Paulo, gained international popularity, and other countries also showed interest.

Thus, 62 giant sculptures of ears, each $2.40 \mathrm{~m}$ in length, were created in a public studio over a period of 2 months and exhibited on the streets (-Figs. 3 and 4). Persons witnessed the giant-ear sculptures and simultaneously received guidance from otolaryngologists and speech therapists on the prevention and treatment of deafness during this period and a public walk through the streets of São Paulo, where the ears were displayed.

\section{Results}

As a social responsibility, this campaign aimed to strengthen the fight against prejudice, which makes it difficult for thousands of people to seek help for a better quality of life by wearing hearing devices. It was a plural and accessible exhibition promoting the democratization of art. It employed local artists, who were responsible for presenting the daily life of the city in art forms.

Establishing healthy behaviors during childhood and youth is more effective than trying to change unhealthy behaviors during adulthood. Therefore, the campaign created a special edition of a children's magazine called "Turma do Bentinho," which was distributed free of charge by the Otorhinolaryngology Foundation (-Fig. 5). This magazine promotes knowledge on strategies for HL prevention and aims to sensitize children to prejudice against individuals with hearing impairment or hearing aids.

In this campaign, audiometry screening tests were also offered to the population. Furthermore, orientation was provided to seek appropriate treatment when indicated.

At the end, an auction was held, and the money raised from selling the sculptures was granted for research on stem cells for hearing, in addition to donating batteries, hearing aids, and cochlear implants and improving the infrastructure for the otology sector of the Hospital das Clínicas (-Fig. 6). Approximately USD 72,000 were raised

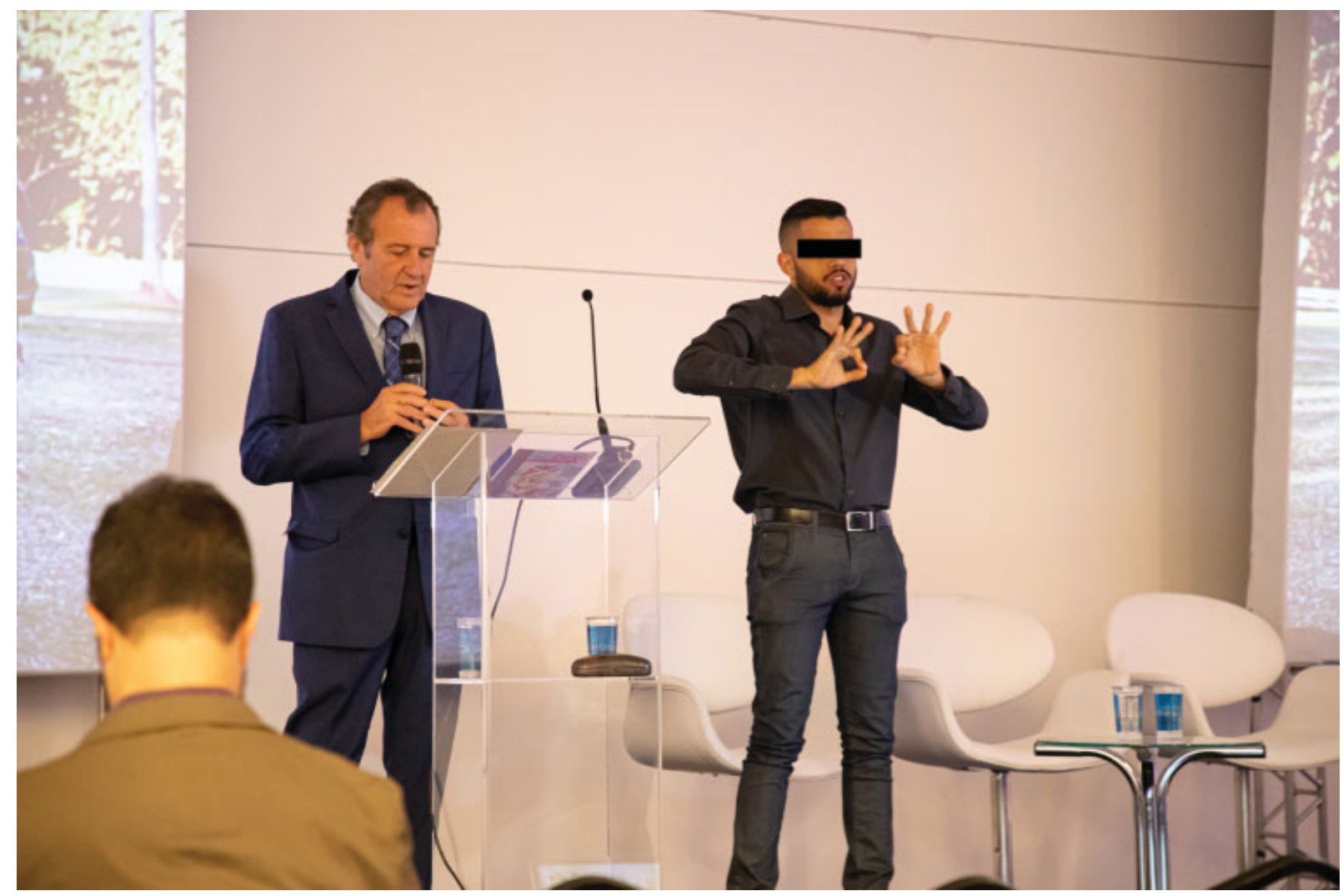

Fig. 6 An auction at the end of the Ear Parade Campaign. 
through the sale of sculptures, as each sculpture was sold at an average of USD 1,500. Furthermore, investments from sponsors raised $>$ USD 240,000. The Ear Parade campaign resulted in spontaneous media coverage, which enlightened people on the effects of deafness on the daily lives of children and adults, reaching $\sim 170$ million people worldwide.

The mission of the exhibition was not only to demystify the use of conventional or implantable hearing devices but also to show the reality of people living with HL and solve their daily difficulties associated with the inaccessibility to any communication using devices, lip reading, and sign language. In addition to the guidance on the prevention and main risk factors for HL in all age groups, people were encouraged to seek an early diagnosis and the various ways to make themselves heard in the society.

Finally, entrepreneurs established a non-governmental organization to directly receive financial resources for the maintenance of hearing aids to be donated to the population.

\section{Discussion}

The WHO defines health prevention as the process that allows people to increase disease control and improve health. Health prevention implies epidemiological knowledge on disease control and risk reduction. It represents a social and political process emphasizing on public policies that seek deeper social changes, including proposals for social education. Cultural campaigns aimed at a target population impact both disease prevention and health promotion for the population at risk.

\section{Conclusion}

Cultural impact is often achieved by combining private investment with the public sector by the dissemination of information. The Ear Parade campaign received investments from private companies, favoring the visibility of their brands as supporters. This alliance enabled public and supplementary health to benefit from reducing the impact of HL.

\section{References}

1 IBGE - Instituto Brasileiro de Geografia e Estatística. Censo 2010 [Internet]. [cited 2019 Oct 04]. Available from: https://censo2010.ibge. gov.br

2 WHO - World Health Organization. WHO global estimates on prevalence of hearing loss [Internet]. Geneva: World Health Organization; 2012. [cited 2019 Oct 04]. Available from: http:// www.who.int/pbd/deafness/WHO_GE_HL.pdf?ua=1

3 Olusanya BO, Neumann KJ, Saunders JE. The global burden of disabling hearing impairment: a call to action. Bull World Health Organ 2014;92(05):367-373. Doi: 10.2471/BLT.13.128728

4 WHO, World Bank World. Report on disability [Internet]. 2011. [cited 2015 Dec 29]. Available from: http://whqlibdoc.who.int/ publications/2011/9789240685215_eng.pdf?ua=1

5 Bento RF, Sousa NC. Hearing Health: A Major Concern for the $2^{\text {st }}$ Century. Int Arch Otorhinolaryngol 2019;23(03):e254-e255. Doi: 10.1055/s-0039-1692980

6 Wilson BS, Tucci DL, Merson MH, O'Donoghue GM. Global hearing health care: new findings and perspectives. Lancet 2017;390 (10111):2503-2515. Doi: 10.1016/S0140-6736(17)31073-5

7 Lederberg AR, Schick B, Spencer PE. Language and literacy development of deaf and hard-of-hearing children: successes and challenges. Dev Psychol 2013;49(01):15-30. Doi: 10.1037/a0029558

8 Mick P, Kawachi I, Lin FR. The association between hearing loss and social isolation in older adults. Otolaryngol Head Neck Surg 2014;150(03):378-384. Doi: 10.1177/0194599813518021

9 Gagné J-P, Southall K, Jennings MB. Stigma and Self-stigma Associated with Acquired Hearing Loss in Adults. Hearing Rev 2011;18 (08):16-22

10 Øhre B, Volden M, Falkum E, von Tetzchner S. Mental Disorders in Deaf and Hard of Hearing Adult Outpatients: A Comparison of Linguistic Subgroups. J Deaf Stud Deaf Educ 2017;22(01): 105-117. Doi: 10.1093/deafed/enw061

11 World Health Organization. Risk Reduction of Cognitive Decline and Dementia: WHO Guidelines [Internet]. Geneva: World Health Organization; 2019. ISBN-13: 978-92-4-155054-3. [cited 2019 Oct 04]. Available from: https://www.who.int/mental_health/ neurology/dementia/guidelines_risk_reduction/en/

12 Liu CM, Lee CT. Association of Hearing Loss With Dementia. JAMA Netw Open 2019;2(07):e198112. Doi: 10.1001/jamanetworkopen. 2019.8112

13 Chern A, Golub JS. Age-related Hearing Loss and Dementia. Alzheimer Dis Assoc Disord 2019;33(03):285-290. Doi: 10.1097/WAD.0000000000000325

14 The Lancet. Prioritising prevention of hearing loss. Lancet 2019; 393(10174):848. Doi: 10.1016/S0140-6736(19)30403-9

15 National Institute for Occupational Safety and Health. Criteria for a recommended standard: occupational noise exposure revised criteria. Cincinnati, OH: US Department of Health and Human Services, CDC, National Institute for Occupational Safety and Health; 1998 